\title{
Sustained reproductive responses in Djungarian hamsters (Phodopus sungorus) exposed to a single long day*
}

\author{
Norah Spears $\uparrow \S$, Cynthia M. Finley $\dagger$, Carol S. Whaling $\ddagger$, \\ Christiana R. Tuthill $†$ and Irving Zucker $\$$ \$ \\ $\dagger$ Department of Psychology and $\ddagger$ Group in Endocrinology, University of California, Berkeley, \\ CA, 94720 USA
}

\begin{abstract}
Summary. Male and female Djungarian hamsters maintained from birth in a short photoperiod ( $8 \mathrm{~h}$ light per day; $8 \mathrm{~L}: 16 \mathrm{D}$ ) showed substantial testicular and uterine growth in response to a single long photoperiod or a 15 -min light pulse that interrupted the 16-h dark period at 18 days of age. These light regimens resulted in heavier testes and uteri at 30 and 35 days of age when compared with those of control animals. Similar results were obtained in hamsters maintained from birth to Day 18 in a long photoperiod (16L:8D), given a single longer day (20L:4D) or constant light on Day 18 and then transferred to a short photoperiod (8L:16D) on Day 19. At 35 days of age animals that received extended light treatment on Day 18 had significantly more developed reproductive structures than did control hamsters. The marked effects of brief light treatment in producing long-term changes in the reproductive axis provide a convenient mammalian model system in which to study neuroendocrine events that underlie photoperiodism.
\end{abstract}

Keywords: pineal gland; gonads; photoperiod; circadian rhythms; reproductive development; hamster

\section{Introduction}

In at least one bird species a single long day produces rapid changes in hormone secretion (Follett et al., 1985). The existence of such responses in Japanese quail has been exploited to examine neuroendocrine bases of photoperiodism (Nicholls et al., 1983; Creighton \& Follett, 1987). The analysis of mammalian photoperiodism would benefit from a comparable model system (Simpson, 1982; Turek, 1982).

Neural investigation of photoperiodism in mammals has been hampered by the length of time animals must be exposed to a change in daylength before a measurable physiological or structural response can be detected. Sluggishness of existing model systems has, for example, precluded assessment of the role of protein synthesis in photoperiodism; it is either impractical or impossible to apply protein synthesis inhibitors continuously for a period of several weeks.

The Djungarian hamster (Phodopus sungorus) is highly responsive to variations in photoperiod. Long daylengths promote gonadal development, somatic growth and a dark summer pelage, while short photoperiods inhibit growth and reproductive development and promote appearance of a white winter pelage (Hoffmann, 1973). The response to a change in daylength is rapid relative to that of other mammals. Transfer from short to long photoperiod increases plasma FSH concentrations within 3 days and testicular weight within 5 days (Simpson et al., 1982). Male Djungarian hamsters raised from birth in a long photoperiod exhibit testicular spermatozoa at 31 days of age

\footnotetext{
*Reprint requests to Dr N. Spears.

\$Present address: MRC Brain Metabolism Unit, University Department of Pharmacology, 1 George Square, Edinburgh EH8 9JZ, UK.
} 
(Hoffman, 1978) and animals transferred at weaning (Day 18) to a short photoperiod fail to undergo gonadal development and have small immature gonads at 35 days of age (Carter \& Goldman, 1983; Yellon \& Goldman, 1984; Milette \& Turek, 1986).

In the course of an experiment on an unrelated topic, several male hamsters that had been reared in long days were exposed to $33 \mathrm{~h}$ of light at weaning (Day 18) and then transferred to a short photoperiod. At 35 days of age their testes were nearly as large as those of males kept from birth to Day 35 in a long photoperiod; males that did not receive constant light on Day 18 and were transferred to the short photoperiod had small undeveloped gonads. These preliminary observations raised the possibility that brief treatment with light at the time of weaning has long-term consequences for reproductive development. The present experiments were undertaken to explore this finding in greater detail.

\section{Materials and Methods}

A breeding colony of Djungarian hamsters (Phodopus sungorus) was maintained in a long photoperiod that provided $16 \mathrm{~h}$ fluorescent light per day $(16 \mathrm{~h}$ light:8 h dark, lights on at 07:00 h, Pacific Standard Time). In 3 experiments females were removed from this colony and mated and housed throughout pregnancy and lactation in a short photoperiod $\left(8 \mathrm{~L}: 16 \mathrm{D}\right.$; lights on at $08: 00 \mathrm{~h}$ ). Room temperature was $23 \pm 2^{\circ} \mathrm{C}$. Animals were provided with food (Mouse Chow $\$ 5015$, Purina Mills, St Louis, MO, USA) and water ad libitum, weaned at 18 days of age and housed singly thereafter in polypropylene cages $(27 \times 16 \times 13 \mathrm{~cm}$ high $)$.

At the end of each experiment hamsters were injected i.p. with a lethal dosage of pentobarbitone sodium, body weight was recorded, and testes and uteri were removed and weighed.

Experiment 1 . Male weanlings $(\mathrm{N}=11)$ were transferred during their normal light phase at 18 days of age to a cabinet that was kept continuously illuminated (light intensity averaged 700 lux at cage level). Experimental hamsters were exposed to light continuously for $33 \mathrm{~h}$ during Days 18-19; on Day 19 they were transferred to a separate room that provided $8 \mathrm{~h}$ light/day (lights on at $08: 00 \mathrm{~h}$ ). A group of control hamsters $(\mathrm{N}=8$ ) remained in the $16 \mathrm{~L}: 8 \mathrm{D}$ until Day 19 and was transferred to the short photoperiod room at the same time as the experimental animals.

Beginning on Day 19, hamsters were housed in cages fitted with running wheels, each connected to a separate channel of an Esterline-Angus event recorder in continuous operation at a chart speed of $45.7 \mathrm{~cm} / 24 \mathrm{~h}$. Each wheel revolution produced a pen deflection. Activity data were recorded for the first 7 days in the $8 \mathrm{~L}: 16 \mathrm{D}$; charts were removed, cut into 24-h segments, and assembled with each day's record placed beneath that from the preceding day. Charts were photographically reduced and labelled. All hamsters were killed at 35 days of age after having been in the $8 \mathrm{~L}: 16 \mathrm{D}$ for 16 days.

Experiment 2. Weanling males $(\mathrm{N}=32)$ were assigned at random to one of 3 groups: some remained in 16L:8D until 70 days of age $(N=11)$, some were kept in 16L:8D until Day 19 and in 8L:16D from Day 19 to Day 70 $(\mathrm{N}=11)$, and the rest were kept in 16L:8D until Day 18, received $33 \mathrm{~h}$ light on Days 18-19 and then were housed in $8 \mathrm{~L}: 16 \mathrm{D}$ from Day $19-70(\mathrm{~N}=10)$. At 70 days testes were removed and weighed.

Experiment 3. Male and female hamsters were weaned at 18 days $(\mathrm{N}=109 ; 12-17$ animals/sex/group). On Day 18 , the light period was extended by $4 \mathrm{~h}$ so that animals received $20 \mathrm{~h}$ of light (lights off at $03: 00 \mathrm{~h}$ instead of at 23:00 h). Control hamsters remained in the standard 16L:8D on Day 18. All animals were transferred to the 8L:16D on Day 19 during their normal light phase and remained in this light regimen until autopsy on Day 30 or 35.

Experiment 4. Adult females were placed in the $8 \mathrm{~L}: 16 \mathrm{D}$ and paired with fecund males. Male offspring ( $\mathrm{N}=9$ ) born to dams housed in $8 \mathrm{~L}: 16 \mathrm{D}$ throughout gestation and lactation were weaned on Day 18 and placed in constant light for $40 \mathrm{~h}$. On Day 19 they were returned to the original 8L:16D. On Day 30, 11 days after exposure to constant light, autopsies were performed. A control group, kept in the $8 \mathrm{~L}: 16 \mathrm{D}$ throughout, was not tested in parallel with these animals since many studies (e.g. Carter \& Goldman, 1983; Hoffmann, 1978), including several in our laboratory, indicate that such animals have completely undeveloped reproductive organs at 30-35 days of age.

Experiment 5. Male weanlings aged 18 days, born to dams kept in $8 \mathrm{~L}: 16 \mathrm{D}$ throughout pregnancy and lactation (see above), remained in $8 \mathrm{~L}: 16 \mathrm{D}$ throughout $(\mathrm{N}=12)$, were transferred to the $16 \mathrm{~L}: 8 \mathrm{D}$ on Day $18(\mathrm{~N}=13)$ or were housed in $8 \mathrm{~L}: 16 \mathrm{D}$ except that on the first night after weaning (Day 19) they received a 15-min light pulse from 22:00 to 22: I $5 \mathrm{~h}(\mathrm{~N}=10)$. All animals were killed on Day 35. Testes were removed, fixed in $10 \%$ formalin and embedded in paraffin wax; sections were cut at $10 \mu \mathrm{m}$, and stained with haematoxylin and eosin. Microscopic analysis of 8 sections per testis was on a 6-point scale (Grocock \& Clarke, 1974), in which '0' represents the presence of Sertoli cells, spermatogonia and a few primary spermatocytes, and ' 5 ' denotes complete spermatogenesis with abundant spermatozoa.

Experiment 6. Hamsters born to dams kept in $8 \mathrm{~L}: 16 \mathrm{D}$ throughout pregnancy and lactation were weaned on Day 18 and alternate littermates either remained in this photoperiod on Day 19 (control group) or had their photophase 
extended by $24 \mathrm{~h}$ so that they were exposed to $32 \mathrm{~h}$ light beginning at $08: 00 \mathrm{~h}$ (experimental group). All animals were maintained in constant darkness from Day 19 to Day 35 at which time autopsies were performed.

Statistical analyses. Experiments with 3 or more groups were subjected to ANOVA (when appropriate). When significant effects were obtained, planned comparisons between two treatment groups were made using Student's $t$ tests. In experiments in which only 2 groups were tested, means were compared with Student's $t$ test. Values were considered significant if $P<0.05$ with 2 -tailed tests.

\section{Results}

\section{Experiment 1: effects of $33 \mathrm{~h}$ of constant light on testicular development and circadian activity rhythms}

Control males, kept in the 16L:8D until Day 19 and in 8L:16D thereafter, had lighter gonads $(160 \pm 63 \mathrm{mg}$, mean \pm s.e.m.) on Day 35 than did experimental animals $(448 \pm 94 \mathrm{mg})$ treated similarly except for exposure to constant light on Day 18-19. The extension of the light phase by $17 \mathrm{~h}$ on Day 18. This extension of the light phase counteracted much of the regressive effect of 8L:16D on Days 19-35.

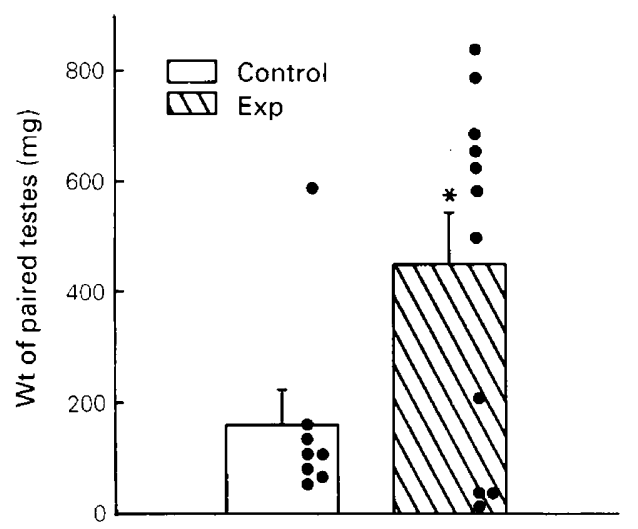

Fig. 1. Paired testes weights at 35 days of age of Djungarian hamsters maintained from birth in 16L:8D and exposed on Day 18 to constant light (Exp; $\mathrm{N}=11$ ) or kept in the $16 \mathrm{~L}: 8 \mathrm{D}$ (Control; $\mathrm{N}=8$ ) (Exp. 1). From Days 19 to 35 animals were housed in 8L:16D. Values are mean \pm s.e.m. ${ }^{*} P<0 \cdot 05$.

Many of the hamsters did not use the running wheels with sufficient frequency during Days 19-26 to permit assessment of entrainment of activity rhythms to the light-dark cycle. Records of 8 animals with activity levels adequate to permit evaluation failed to indicate differences in activity onsets between the experimental and control groups, but the small sample size, substantial variability, and the fact that animals were in the process of entraining to the $8 \mathrm{~L}: 16 \mathrm{D}$, preclude firm conclusions. Stable entrainment was not evident by the end of the first week in 8L:16D (Fig. 2). Nevertheless, one animal (No. 15) exposed to constant light on Day 18 had phase angles of activity onset similar to those of a control animal (No. 23) but gonadal weight was much greater in the former than in the latter $(634 v s 131 \mathrm{mg})$.

One control animal (No. 13) entrained to the $8 \mathrm{~L}: 16 \mathrm{D}$ and activity began approximately $8 \mathrm{~h}$ after the beginning of the dark phase; in agreement with previous observations (Eskes \& Zucker, 1978) and predictions from theory (Elliott, 1976), its gonads were well developed (594 mg).

\section{Experiment 2: effects of constant light on Day 18 on testes at 70 days of age}

There was a significant effect of treatment $(\mathrm{F}=15.7 ; P<0.01)$ due to the difference in testes weights between $16 \mathrm{~L}: 8 \mathrm{D}$ control animals $(855 \pm 32 \mathrm{mg})$ and the other two groups. Differences in 


\begin{tabular}{|c|c|c|c|c|c|c|c|c|c|c|c|c|}
\hline \multicolumn{13}{|c|}{ Hours } \\
\hline $12: 00$ & $14: 00$ & $16: 00$ & $18: 00$ & $20: 00$ & $22: 00$ & $24: 00$ & $02: 00$ & $04: 00$ & $06: 00$ & $08: 00$ & $10: 00$ & $12: 00$ \\
\hline
\end{tabular}

$15 \mathrm{LL}$
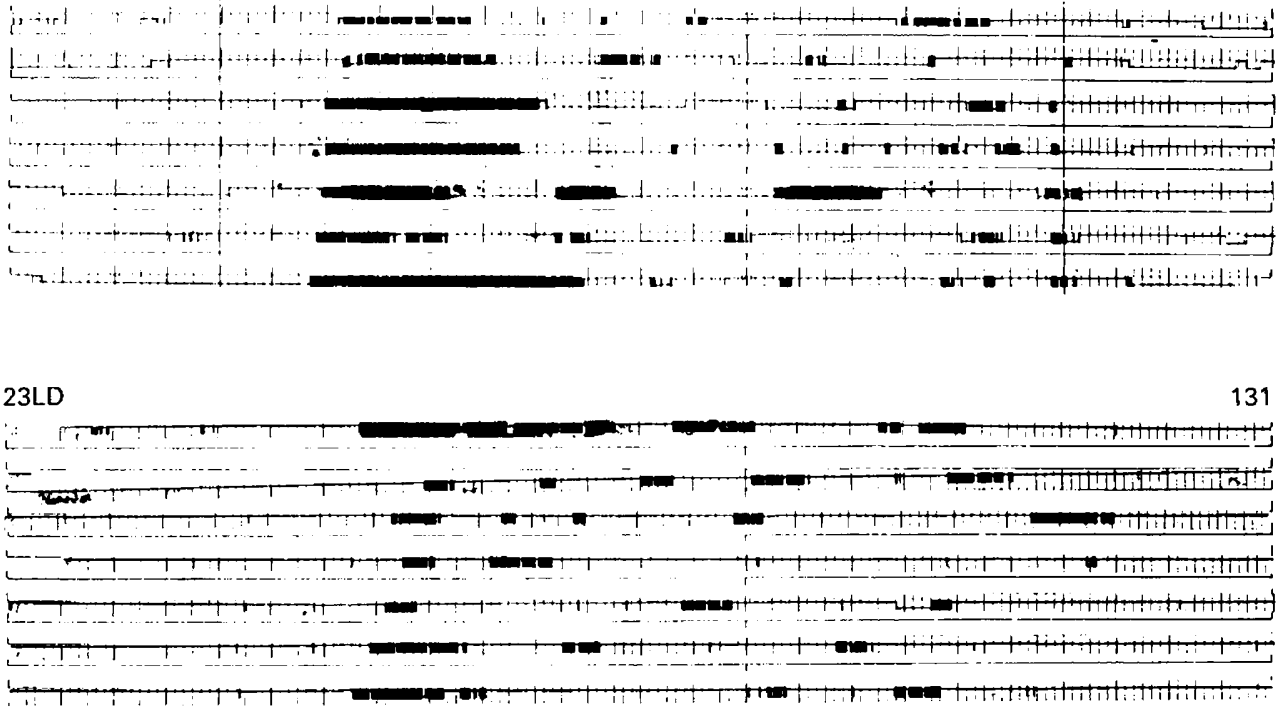

13LD

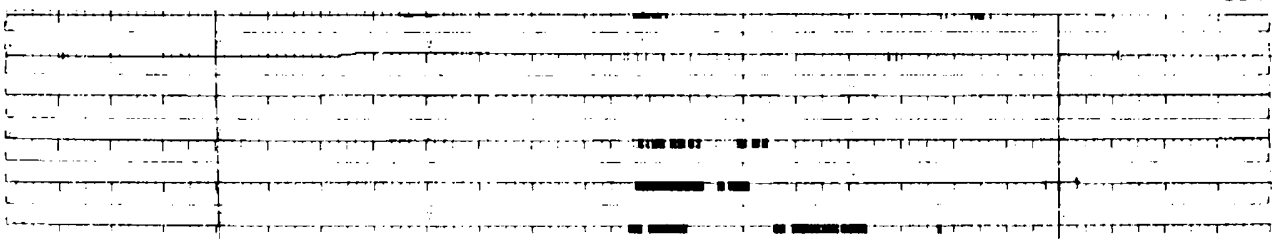

Fig. 2. Wheel-running activity records of hamsters on Days 19-26 of age during maintenance in an $8 \mathrm{~L}: 16 \mathrm{D}$ photoperiod (Exp. 1). The dark phase is indicated by the black bar at top of the panel. Animals were kept in 16L:8D from birth to Day 18 and exposed to the $16 \mathrm{~L}: 8 \mathrm{D}$ cycle (LD values) or to constant light (LL values) on Day 18. Paired testes weights ( $\mathrm{mg}$ ) for each hamster on Day 35 are shown at the top right of each actogram.

testes weight between groups of hamsters exposed to constant light or 16L:8D on Days 18-19 were not significant at Day $70(P=0.2)$; however, mean testis mass was more than twice as great in the former group $(371 \pm 133 \mathrm{mg}$ vs $160 \pm 89 \mathrm{mg})$ and a greater percentage of individuals treated with constant light on Day 18 had large well developed gonads even after more than 7 weeks in $8 \mathrm{~L}: 16 \mathrm{D}$. Gonadal and body weights of hamsters kept in 16L:8D throughout were significantly greater than those of the other two groups.

\section{Experiment 3: influence of a single 4-h extension of the light phase on reproductive development}

Males. Testes were heavier on Day 30 and Day $35(P<0.01$ in each case $)$ in hamsters for which the photophase was extended by $4 \mathrm{~h}$ on Day 18 only (20L:4D) compared to gonads of animals that remained in the 16L:8D photoperiod (Fig. 3). Differences between groups were substantially 
greater on Day 35 than on Day $30(252 \%$ vs $57 \%)$. Body weights were significantly higher on both Days 30 and 35 in animals that had received the extended photophase on Day $18(27 \pm 1 \mathrm{vs}$ $23 \cdot 6 \pm 1 \mathrm{~g}, P<0 \cdot 01$, on Day $35 ; 26 \cdot 1 \pm 1$ vs $23 \cdot 7 \pm 1, P<0 \cdot 01$, on Day 30 ).
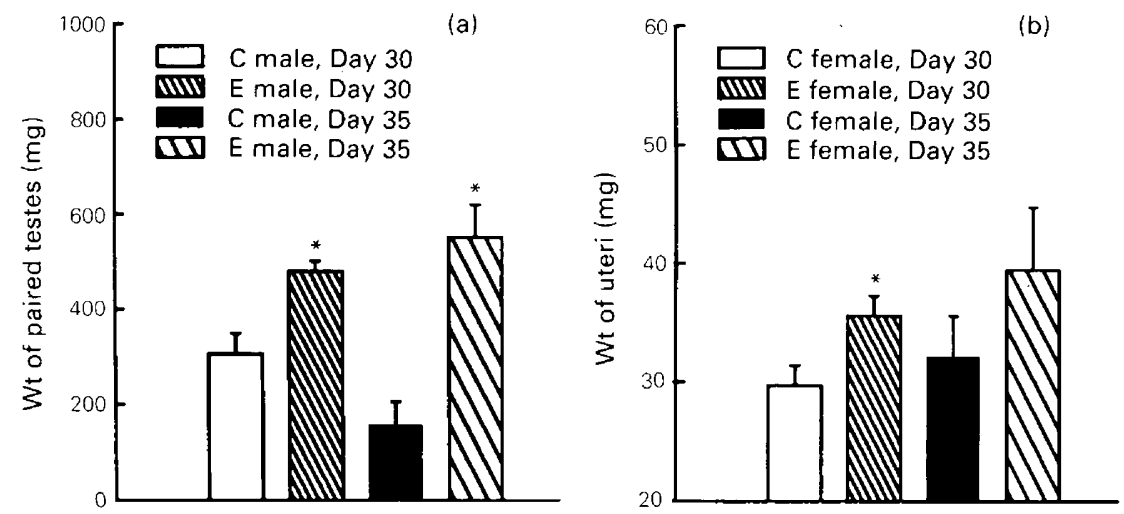

Fig. 3. Weights of the testes (a) and uteri (b) at 30 and 35 days of age of hamsters kept from birth until Day 18 in 16L:8D photoperiod (12-17 hamsters/group). On Day 18 control animals were kept in this same photoperiod (C male; $C$ female) and experimental hamsters in 20L:4D (E male; E female). From Day 19 until autopsy, hamsters were housed in 8L:16D (Exp. 3). ${ }^{*} P<0.05$ compared with age-matched control group.

Females. Uteri were heavier at 30 days $(P<0.05)$ but not at 35 days of age $(P=0.3$ : Fig. 3$)$ in females exposed to the 20L:4D photocycle on Day 18; body weights were not affected by this treatment at either age.

Experiment 4: effects of constant light on Day 18 on animals kept in a short photoperiod from birth until Day 30

Males kept in $8 \mathrm{~L}: 16 \mathrm{D}$ throughout gestation and lactation and exposed to $40 \mathrm{~h}$ of constant light on Day 18-19, had paired testes weights of $237 \pm 59 \mathrm{mg}$ on Day 30 ; this value is much higher than the gonadal weights of animals housed in $8 \mathrm{~L}: 16 \mathrm{D}$ but not exposed to constant light $(33 \pm 4 \mathrm{mg}$, Exp. 5). Exposure to constant light for $40 \mathrm{~h}$ thus induces substantial gonadal growth in animals otherwise kept in $8 \mathrm{~L}: 16 \mathrm{D}$.

\section{Experiment 5: effect of a single 15-min light pulse on Day 18 on gonadal development of hamsters in 8L:16D}

A brief light pulse given $6 \mathrm{~h}$ after onset of the dark phase on Day 18 to hamsters housed in an 8L:16D resulted in significant testicular growth. There was a significant overall treatment effect $(\mathrm{F}=28.87 ; P<0.01)$. Testes weights and the spermatogenic index were significantly greater in the animals given the light pulse than in control hamsters $(P<0.05$, Fig. 4).

Experiment 6: effects of constant light on Day 18 on reproductive development of hamsters housed in darkness from Day 19 to Day 35

Hamsters that received $32 \mathrm{~h}$ of constant light on Day 18 had heavier testes and uteri than did control animals $(P<0.01$ in each case; Fig. 5). Body weights did not differ significantly between experimental and control groups of either sex. 

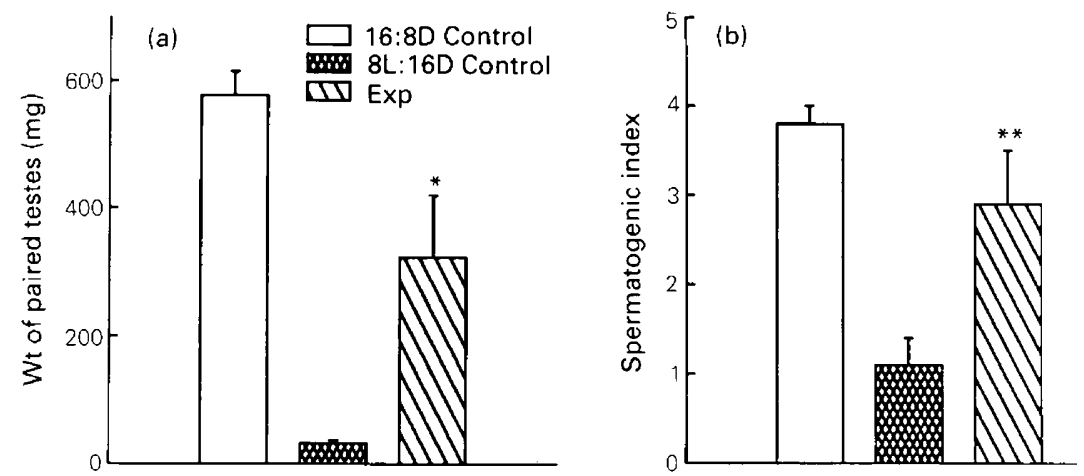

Fig. 4. Weights of the testes (a) and spermatogenic index (b) at 35 days of age of hamsters kept in 8L:16D until Day 17. Starting on Day 18 one group of animals was kept in 8L:16D until Day 35 (8L:16D control; $N=13$ ), another was transferred and kept in 16L:8D until Day 35 (16L: $8 \mathrm{D}$ control; $\mathrm{N}=12$ ), and a third group received a 15 -min light pulse $6 \mathrm{~h}$ after the onset of the dark phase and was returned to $8 \mathrm{~L}: 16 \mathrm{D}$ until Day $35($ Exp; $\mathrm{N}=10)($ Exp. 5$) .{ }^{*} P<0.05$ compared with each control group.

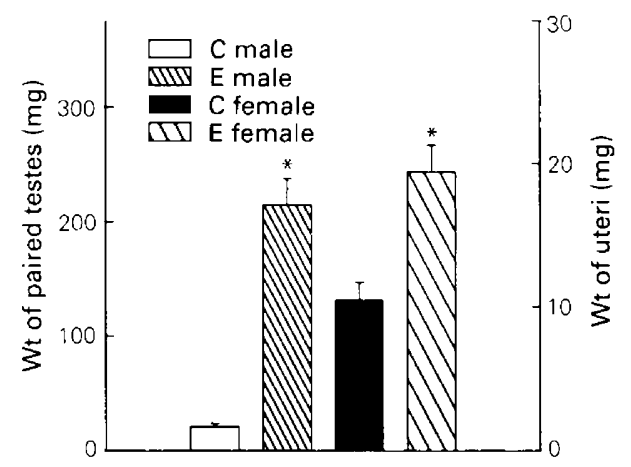

Fig. 5. Weights of testes and uteri at 35 days of age of hamsters maintained until Day 18 in 8L:16D (7-16 hamsters per group). On Day 18 animals remained in $8 \mathrm{~L}: 16 \mathrm{D}$ (C male; $\mathrm{C}$ female) or were exposed to constant light (E male; E female). From Days 19 to 35 hamsters were kept in constant darkness (Exp. 6). ${ }^{*} P<0.01$ compared with same-sexed control group.

\section{Discussion}

Djungarian hamsters kept from birth in a long photoperiod and exposed to an extended light period on the day before transfer to a short photoperiod (Day 18) had much heavier testes and higher body weights at 30 and 35 days of age than did animals not given the extra light treatment. An extra $4 \mathrm{~h}$ of light on the day of weaning had a sustained effect on development of the reproductive system of male and female animals sampled 17 days later. When the duration of the photophase was extended by only 50 min on Day 18 , photostimulation was not observed at 35 days in most hamsters (C. M. Finley, C. S. Whaling \& I. Zucker, unpublished observations), suggesting that the photoperiod must be extended by several hours to observe long term effects on the reproductive axis.

Photostimulation of the reproductive axis also was observed at Day 35 in hamsters kept in a short photoperiod through Day 18 then exposed for 1 day to an extended light period. These results indicate that in prepubertal Djungarian hamsters with different photoperiodic histories a single 
long day alters neuroendocrine activity in a sustained fashion, resulting in substantial gonadal development several weeks later. Light treatment at weaning presumably initiates increased secretion of gonadotrophin hormone releasing hormone (GnRH) over a period of several days. Whether brief photostimulation at weaning renders the pituitary more responsive to $\mathrm{GnRH}$ is unknown. In Japanese quail, in which similar photostimulation phenomena have been observed, there is no evidence for enhanced sensitivity to luteinizing hormone-releasing hormone (Follett et al., 1977) or increased hypothalamic GnRH content (Creighton \& Follett, 1987).

The effects of 1 day of photostimulation at weaning were evident at 35 days of age but were not statistically significant at Day 70 , although several hamsters still had substantially stimulated gonads after 52 days in the short photoperiod. The counteractive effect of extending the photophase on Day 18 on responsiveness to short daylengths is not permanent; nor is it likely that photostimulation renders animals refractory to short daylengths. We suggest that the short photoperiod is detected normally in these animals, but that transduction of this information into altered endocrine activity is delayed as a consequence of the prior photostimulatory signal.

The reproductive response of weanling Djungarian hamsters to one long(er) day ensures that animals departing the nest for the first time may require only a single exposure to long or increasing daylengths to stimulate development of the reproductive apparatus. In nature, increasing daylengths are predictive of the breeding season for Djungarian hamsters (Weiner, 1987); a sustained reproductive response to a single long day may safeguard hamsters from reproductive failure if they are not exposed to a series of long photoperiods. Whether a single long day is adequate to induce mating behaviour and successful production of young is unknown.

Castration greatly increases sensitivity of the gonadotrophin release apparatus to long photoperiods in hamsters and quail (Simpson et al., 1982; Turek, 1982; Nicholls et al., 1983). The prepubertal state of hamsters in the present experiments, particularly low steroid hormone concentrations, may have contributed to the increased responsiveness to the long photoperiod. Whether similar effects can be obtained with postpubertal hamsters in which the gonads have undergone regression in short photoperiods is presently under investigation.

Simpson (1982) and Turek (1982) previously documented increased plasma FSH concentrations in castrated male Syrian hamsters 3 days after exposure to a single long day. These responses were of low magnitude and short lived and effects of the single long day on gonadal growth were not assessed. A more robust and sustained increase in FSH concentrations has been documented in preliminary experiments with Djungarian hamsters using the paradigm described in the present report (C. S. Whaling, C. M. Finley, N. Spears, P. Licht \& I. Zucker, unpublished observations).

Interruption of the $16 \mathrm{~h}$ night by $15 \mathrm{~min}$ of light on the day of weaning stimulated gonadal growth in prepubertal hamsters. Night interruption experiments of this type, extended over many weeks in hamsters otherwise maintained in non-stimulatory photoperiods, produce gonadal and somatic growth in Djungarian (Hoffmann et al., 1981; Milette \& Turek, 1986) and Syrian (Ellis \& Follett, 1983; Earnest \& Turek, 1984) hamsters. Such experiments cannot, however, be used to delineate the photoinducible phase. The latter can be defined with certainty in this paradigm only if the animal responds photoperiodically to a single stimulatory cycle; if this does not occur, there is the potentially confounding complication that repeated night interruptions phase shift the photoinducible phase (Nicholls et al., 1983). The present paradigm will permit delineation of the photoinducible phase in Djungarian hamsters; such information presently is available for only one mammal, the Syrian hamster, and was derived with a different, more problematic procedure (Elliott, 1976).

Changes in the synthesis and release of melatonin transduce the effects of daylength on the neuroendocrine-gonadal axis of male Djungarian hamsters. Long and short durations of elevated melatonin titres signify short and long days, respectively (Carter \& Goldman, 1983). Changes in the duration of the nighttime melatonin peak and the animals' prior photoperiodic history also influence whether the gonadal system undergoes involution (Hoffmann et al., 1986). In the present 
experiments, light extensions experienced by hamsters in 16L:8D (20L:4D or constant light), or by animals in $8 \mathrm{~L}: 16 \mathrm{D}$ (15-min light pulses given in the middle of the night or constant light), may decrease the duration of nighttime melatonin secretion for one or more days (see Illnerova \& Vanecek, 1987) and thereby provide the physiological basis for the photostimulatory effect.

Development of the reproductive system in hamsters housed in short daylengths from Day 19 to Day 35 could reflect phase-shifting of the animals' circadian rhythms by the light treatment on Day 18. If this occurred, hamsters would entrain to the short photoperiod so that light coincided with the photoinducible phase (Eskes \& Zucker, 1978). Two lines of evidence argue against this interpretation. The wheel-running patterns of hamsters photostimulated on Day 18 and transferred to short days did not indicate such phase shifts in the circadian system. More particularly, animals kept in constant darkness after receiving extended light treatment on Day 18 had well stimulated reproductive organs 17 days later. Altered entrainment to the short photoperiod, therefore, is not necessary for a single long day to induce gonadal growth.

A major limitation in studying the neurobiology of mammalian photoperiodism is circumvented by the paradigm described herein. Reliable elicitation of robust photoperiodic responses to a single long(er) day should prove useful in elaborating formal properties and physiological substrates of the system that regulates seasonal breeding in rodents.

We thank Cecile Gunn, Rick Lauraya, and Kimberly Pelz for technical assistance, Norman Mattox, Joan Wallace, Katie Hertel, Kathy Moorehouse and Cathy Doherty for animal care; Paul Haller for photographing the illustrations; and John Dark and Elena Thomas for helpful criticism of an earlier version of the manuscript. This research was supported by NIH grant HD-02982.

\section{References}

Carter, D.S. \& Goldman, B.D. (1983) Antigonadal effects of timed melatonin infusions in pinealectomized male Djungarian hamsters (Phodopus sungorus sungorus): duration is the critical parameter. Endocrinology 113, $1261-1267$.

Creighton, J.A. \& Follett, B.K. (1987) Changes in GnRH and LH in Japanese quail during the first few days of photostimulation. $J$. Endocr. 113, 419-422.

Earnest, D.J. \& Turek, F.W. (1984) Periodic exposure to a brief light signal stimulates neuroendocrinegonadal activity in golden hamsters. J. Androl. 5, 64-69.

Elliott, J.A. (1976) Circadian rhythms and photoperiodic time measurement in mammals. Fedn Proc. Fedn Am. Socs exp. Biol. 35, 2339-2346.

Ellis, D.H. \& Follett, B.K. (1983) Gonadotropin secretion and testicular function in golden hamsters exposed to skeleton photoperiods with ultrashort light pulses. Biol. Reprod. 29, 805-818.

Eskes, G.A. \& Zucker, 1. (1978) Photoperiodic regulation of the hamster testis: Dependence on circadian rhythms. Proc. natn. Acad. Sci. USA 75, 1034-1038.

Follett, B.K., Davies, D.T. \& Gledhill, B. (1977) Photoperiodic control of reproduction in Japanese quail: changes in gonadotrophin secretion on the first day of induction and their pharmacological blockade. $J$. Endocr. 74, 449-460.

Follett, B.K., Foster, R.G. \& Nicholls, T.J. (1985) Photoperiodism in birds. In Photoperiodism, Melatonin and the Pineal (Ciba Fdn Symp. No. 117), pp.93-105. Pitman, London.
Grocock, C.A. \& Clarke, J.R. (1974) Photoperiodic control of testis activity in the vole, Microtus agrestis. $J$. Reprod. Fert. 39, 337-347.

Hoffmann, K. (1973) The influence of photoperiod and melatonin on testis size, body weight and pelage colour in the Djungarian hamster (Phodopus sungorus). J. Comp. Physiol. 95, 267-282.

Hoffmann, K. (1978) Effects of short photoperiods on puberty, growth and moult in the Djungarian hamster (Phodopus sungorus). J. Reprod. Fert. 54, $29-35$.

Hofimann, K., Illnerova, H. \& Vanecek, J. (1981) Effect of photoperiod and of one minute light at night-time on the pineal rhythm on $\mathrm{N}$-acetyltransferase activity in the Djungarian hamster Phodopus sungorus. Biol. Reprod. 24, 551-556.

Hofimann, K., Illnerova, H. \& Vanecek, J. (1986) Change in duration of the nighttime melatonin peak may be a signal driving photoperiodic responses in the Djungarian hamster (Phodpus sungorus). Neurosci. Letl. 67, 68-72.

Illnerova, H. \& Vanecek, J. (1987) Entrainment of the circadian rhythm in the rat pineal $\mathrm{N}$-acetyltransferase activity by prolonged periods of light. J. comp. Physiol. A 161, 495-510.

Milette, J.J. \& Turek, F.W. (1986) Circadian and photoperiodic effects of brief light pulses in male Djungarian hamsters. Biol. Reprod. 35, 327-335.

Nicholls, T.J., Follett, B.K. \& Robinson, J.E. (1983) A photoperiodic response in gonadectomized Japanese quail exposed to a single long day. J. Endocr. 97, $121-126$. 
Simpson, S.M. (1982) Rapid photoperiodic response in golden hamsters. IRCS Medical Sciences 10, 679-680.

Simpson, S.M., Follett, B.K. \& Ellis, D.N. (1982) Modulation by photoperiod of gonadotrophin secretion in intact and castrated Djungarian hamsters. J. Reprod. Fert. 66, 243-250.

Turek, F.W. (1982) Rapid increase of serum FSH levels in castrated male hamsters following transfer from short to long days or exposure to a single long day. Endocrinology 111, 332-334.
Weiner, J. (1987) Limits to energy budget and tactics in energy investment during reproduction in the Djungarian hamster (Phodopus sungorus sungorus Pallas 1770). Symp. zool. Soc. Lond. 57, 167-187.

Yellon, S.M. \& Goldman, B.D. (1984) Photoperiodic control of reproductive development in the male Djungarian hamster (Phodopus sungorus). Endocrinology 114, 664-670.

Received 14 August 1989 